УДК 343.119

DOI: $10.17223 / 22253513 / 27 / 9$

\title{
М.К. Свиридов
}

\section{СУДЕБНАЯ ВЛАСТЬ, ЕЕ ПРОЯВЛЕНИЕ В УГОЛОВНОМ ПРОЦЕССЕ}

\begin{abstract}
В связи с закрепленным Конституцией Российской Федерации разделением властей судебная власть как самостоятельная ветвь власти должна выполнять не только свою работу (разрешение уголовных дел), но и осуществлять сдерживающе-контрольную деятельность в отношении других ветвей власти. В связи с этим содержание судебной власти увеличилось. Контрольно-сдержсивающая деятельность не входит в правосудие, являясь самостоятельным элементом судебной власти, у нее свои предмет и метод. Наличие в уголовном судопроизводстве двух элементов с разными предметами и методами способно привести к сметению методов и размывванию требуемого для правосудия жесткого метода, поскольку метод другого элемента весьма мягок. В статье предлагаются меры, способные предотвратить искажение метода правосудия.

Ключевые слова: судебная власть, правосудие, судебный контроль.
\end{abstract}

В советское время вопрос о проявлении судебной власти в уголовном процессе решался несложно. Во-первых, как самостоятельной судебной власти не было, она являлась частью единой государственной власти. Вовторых, в уголовном процессе она была необходима только для разрешения уголовных дел, т.е. для осуществления правосудия. Поэтому осуществление правосудия и проявление судебной власти практически означали одно и то же.

Положение сильно изменилось после закрепления в ст. 10 Конституции Российской Федерации разделения властей. Судебная власть стала, наряду с законодательной и исполнительной, самостоятельной и независимой ветвью власти.

В соответствии с разделением властей каждая ветвь власти осуществляет две функции: боту);

- осуществляет то дело, ради которого она создана (т.е. делает свою ра-

- кроме этого, каждая ветвь власти должна быть системой сдержек и противовесов для других властей, удерживая их от выхода за пределы своего назначения. В этом проявляется реализация разделения властей.

Изложенные положения полностью относятся и к судебной власти, которая сейчас выполняет тоже две функции: делает свою работу (осуществляет правосудие) и является сдержкой и противовесом (исполняя контрольно-сдерживающую функцию). В лице Конституционного Суда РФ осуществляется сдержка законодательной власти; что касается уголовной 
юстиции, то в этой сфере суды являются сдержкой действующей в уголовном процессе исполнительной власти - следственных органов. Причем последний вид судебной деятельности в уголовном процессе занимает значительное место - это и разрешение жалоб на действия (бездействия), и решения следователей, и получение следователем разрешения суда на производство целого ряда следственных действий.

Таким образом, если ранее судебная деятельность в уголовном процессе была однозначной - только осуществление правосудия, то в настоящее время у суда в уголовном процессе появился еще один обязательный вид деятельности - контрольно-сдерживающий по отношению к исполнительной власти. В связи с этим возник целый ряд проблем, требующих разрешения. Так, необходимо четко определить: характер отношений судебной власти с другими ветвями власти, участвующими в разрешении уголовного дела; каким стал предмет судебной власти в уголовном процессе; осталась ли судебная власть в уголовном процессе однородной, а если нет, то из каких элементов она должна состоять и какими должны быть взаимоотношениями между элементами и т.п. Решение этих и других аналогичных им проблем необходимо для полноценной судебной реформы и создания нового Уголовно-процессуального кодекса с единой методологией.

Представляется, что отрицать наличие в судебной деятельности в уголовном процессе двух разных ее видов невозможно. Нельзя не отметить, что между ними есть немало общего. Осуществляются они одним судьей в рамках одного уголовного дела. Причем контрольно-сдерживающая деятельность осуществляется для обеспечения успешного правосудия: суд разрешает следователю произвести необходимое для получения нужного доказательства следственное действие; рассмотрев жалобу на решение следователя, суд побуждает следователя исправить ошибку и добиться нужного результата. Поэтому прав А.Д. Бойков, который писал, что «надзорная функция суда является для него субсидиарной, выполняемой лишь при осуществлении главной функции - правосудия» [1. С. 226].

Отмеченное общее позволяет некоторым авторам считать, что контрольно-сдерживающая деятельность суда не является самостоятельным элементом судебной власти, которая, как и прежде, однозначна и проявляется в уголовном процессе только в виде правосудия. Так, В.А. Лазарева считает, что судебный контроль представляет собой не самостоятельный элемент судебной власти, а является особой формой осуществления правосудия [2. С. 57]. Иначе говоря, увеличилась сфера правосудия, проявление же судебной власти осталось прежним - однозначным - только в осуществлении правосудия.

С таким мнением, как думается, вряд ли можно согласиться. Несмотря на наличие в анализируемых элементах судебной власти общего, у них гораздо больше различий. Представляется правильным мнение тех авторов, которые считают контрольно-сдерживающую деятельность суда в уголовном процессе самостоятельным элементом судебной власти. Так полагает Л.А. Воскобитова [3]. Она пишет, что функция судебного контроля по отношению к 
другим ветвям власти возложена на судебную власть наряду с правосудием, т.е. как самостоятельный элемент, отдельный от правосудия [3. С. 122]. Аналогичное мнение высказывают В.А. Азаров и И.Ю. Таричко, которые пишут: «Судебный контроль является самостоятельной функцией суда, одним из средств реализации судебной власти. Понятие "правосудие" не охватывает указанных контрольных полномочий суда» [4. С. 181]. В.А. Азаров и И.Ю. Таричко определяют эти полномочия, но задачи правосудия туда не входят [Там же. С. 148]. В то же время указанные авторы подчеркивают, что судебный контроль «не является правосудием, но осуществляется во имя правосудия» [Там же. С. 137]. Отрывать друг от друга эти два элемента судебной власти нельзя, только оба они в совокупности обеспечивают успешное проявление судебной власти в уголовном процессе.

Таким образом, следует согласиться с авторами, признающими контрольно-сдерживающую деятельность суда самостоятельным элементом судебной власти. Подтверждением этому служит следующее.

Как уже отмечалось, при наличии общего в анализируемых элементах судебной власти больше различного.

Главное различие - у них разные задачи, предмет и метод правового регулирования.

Если задачей правосудия является применение норм уголовного права и правильное выяснение виновности или невиновности подсудимого, то при осуществлении контрольно-сдерживающей деятельности задачи применения норм уголовного права нет и ничья виновность не выясняется; тут стоит совсем иная задача - обеспечить правомерность действий следователя. Отсюда вытекают различия в предметах деятельности рассматриваемых элементов судебной власти: предметом правосудия является изучение вопроса о наличии или отсутствии преступления, виновности или невиновности подсудимого, назначении виновному наказания или освобождении от него. Предмет контрольно-сдерживающей деятельности совсем иной: анализ деятельности следователя с целью определить, не было ли каких либо отклонений от установленных правил и правомерны ли намерения следователя произвести какие-либо действия.

Еще больше отличий в методах правового регулирования. Поскольку уголовный процесс имеет дело с самой жесткой, причем, карательной отраслью права - уголовного, метод правового регулирования правосудия должен быть очень жестким. Он необходим, чтобы не допустить ошибки в применении кары. Его основными чертами можно назвать следующее.

Во-первых, деятельность суда при осуществлении правосудия должна быть облачена в жесткую процессуальную форму, и только достигнутые в рамках этой формы результаты могут признаваться юридически значимыми. Наличие уголовно-процессуальной формы предполагает почти детальное закрепление в законе процедуры производств, действий органов власти. Действия, не соответствующие закрепленным правилам, уничтожают юридическую значимость получаемого результата, каким бы важным он ни был по содержанию. 
Во-вторых, деятельность суда (как, впрочем, и других действующих в уголовном процессе органов власти) должна быть в максимальной мере детально урегулирована законом и допускать минимум усмотрения органов власти. Несомненно, полностью избежать усмотрения органов власти невозможно, однако оно должно быть минимальным и быть вызвано серьезными причинами, чтобы избежать произвола.

В-третьих, осуществление правосудия должно быть насыщено властностью, чтобы можно было заставить субъектов уголовного процесса действовать в соответствии с законом и - в рамках закона - в интересах разрешаемого уголовного дела.

В-четвертых, отношения органов власти с иными субъектами в уголовном процессе должны существовать в форме властных распоряжений, обязательных для исполнения.

В-пятых, уголовный процесс должен быть снабжен набором мер принуждения - от самых мягких до самых жестких (заключение под стражу). Это необходимо, чтобы пресечь уклонение от правосудия не только обвиняемого (подсудимого), который нередко пытается скрыться от суда, но и свидетелей, которые также нередко пытаются не являться в суд, отказываться давать показания или давать ложные показания.

Таковы основные черты метода правового регулирования в правосудии. Ничего даже близкого к этому нет в методе регулирования контрольносдерживающей деятельности суда (второго элемента судебной власти).

Прежде всего необходимо отметить, что судебный контроль не является правосудием, эти два вида судебной деятельности разнохарактерны. Правосудие - это разрешение уголовного дела. Предмет судебного контроля, как уже отмечалось, иной: анализ правомерности действий или намерений следователя. Поэтому здесь нет необходимости в такой жесткости метода правового регулирования, какой нужен при осуществлении правосудия. Здесь не нужна жесткая процессуальная форма, нет необходимости в детальной правовой регламентации - многие вопросы могут быть решены судейским усмотрением. Порядок разрешения ходатайств ст. 122 УПК РФ вообще не регламентирован; несколько подробнее, но также без детализации регулирует ст. 125 УПК РФ порядок рассмотрения жалоб на действия и решения следователя. Властность присутствует и здесь, однако она тоже закреплена в смягченной форме. Например, если суд признает решение следователя необоснованным и обяжет следователя устранить нарушение, при неисполнении этой обязанности никаких санкций к следователю со стороны суда закон не предусматривает, разногласия здесь разрешаются другими, более мягкими мерами. Более свободным является положение субъектов, у них больше субъективных прав, никаких мер принуждения к субъектам при осуществлении судебного контроля в законе не предусмотрено, следовательно, применяться не могут.

Как видно, различия в методах правового регулирования правосудия и судебного контроля весьма большие. Они (методы) разнотипны. Пользуясь классификацией С.С. Алексеева, метод регулирования правосудия являет- 
ся централизованным, императивным; метод же судебного контроля можно отнести (хотя и не во всех чертах) к децентрализованному [5. С. 224].

Таким образом, мы наблюдаем довольно необычное явление: в одном кодексе (УПК РФ) оказались нормы права с разными предметами и методами правового регулирования.

Количество и тех, и других значительное (и, думается, в будущем количество норм судебного контроля будет увеличиваться). Но совокупность правовых норм, имеющих самостоятельные специфические предметы и методы правового регулирования, образуют самостоятельную отрасль права. С.С. Алексеев писал: «В каждый данный момент наличие особого юридического режима регулирования и его наиболее характерных для основных отраслей черт - специфического метода и механизма регулирования (которые проявляются прежде всего в особенностях правового статуса субъектов) - служит непосредственным и притом практически важным безошибочным показателем того, что пред нами реально существующее подразделение в правовой системе, самостоятельная отрасль права» [6. С. 193]. Следовательно, УПК РФ закрепляет нормы двух отраслей права: уголовно-процессуального, регулирующего правосудие, и конституционного, регулирующего сдерживание исполнительной власти (судебный контроль). Именно к конституционному праву, как думается, следует отнести нормы, регулирующие судебный контроль, поскольку здесь осуществляется конституционная функция, вытекающая из разделения властей.

В нашей системе права есть отрасли, где содержатся нормы разных отраслей права. Но такое имеет место в комплексных отраслях, которые являются вторичными. Уголовно-процессуальная отрасль не вторичная (как и конституционная отрасль), а основная, и смешение в ней норм разных отраслей права вряд ли допустимо, оно причиняет вред. Ведь несмотря на большую близость уголовно-процессуального и уголовного права, смешения их норм нет, так как обе эти отрасли основные, имеющие разные предметы и методы правового регулирования.

В тексте УПК РФ заметна особенность: нормы, относящиеся к различным отраслям права, находясь в одном законе, не структурированы, а смешаны со всеми другими нормами. В этом кроется серьезная опасность. Дело в том, что существующий уголовный процесс, включающий в себя часть норм конституционного права, является системой, где действуют системные закономерности. Все элементы единой системы должны быть однородными (иначе систему будут подрывать противоречия) и связанными друг с другом. Более того, все элементы системы не только находятся рядом друг с другом, но они оказывают друг на друга влияние. Об этом писал видный теоретик права С.С. Алексеев: «Иногда даже простое перемещение нормативных предписаний из одной области законодательства в другую, близкую ей область приводит к тому, что эти предписания включаются в новую систему связей, в силовое поле нового правового режима, а значит приобретают новые правовые свойства» [6. С. 67]. Нахождение в «жестком» уголовном процессе достаточно большого количества норм 
«мягкого» конституционного права способно привести к размыванию уголовно-процессуального метода правового регулирования. Это опасно, поскольку уголовный процесс обеспечивает применение «жесткого» уголовного права. Сейчас можно сказать, что существующий уголовный процесс не имеет единого, четко выраженного метода правового регулирования. В нем действуют два метода: централизованный (жесткий) и децентрализованный (мягкий), что крайне вредно. Поскольку в УПК РФ закреплен, кроме жесткого, и мягкий, упрощенный метод, это побуждает законодателя предписывать в целях экономии средств и по иным причинам применение мягкого метода к работе с деяниями, признаваемыми самим законодателем преступлениями, в том числе и тяжкими. Примером такого положения является наличие в УПК РФ упрощенных производств (гл. 32-1, 40 и 40-1). Здесь искажение уголовно-процессуального метода проявляется в нарушении всегда действующей обоснованной схемы судебного разбирательства - отсутствии судебного следствия по делам с признанием подсудимого виновным и при соглашении о сотрудничестве. В УПК РФ неоднократно встречается словосочетание «постановление приговора без судебного разбирательства» (ст. 314, 316 УПК РФ). При разбирательстве таких дел суд отстранен от непосредственного исследования доказательств, на которых он будет основывать приговор. Один из важнейших принципов установления истины - непосредственности - исключен. Часть 5 ст. 316 гласит: «Судья не проводит в общем порядке исследование и оценку доказательств, собранных по уголовному делу». Убеждаться в виновности подсудимого суд может только по материалам следователя. Фактически судья, выносящий приговор, с доказательствами работать не обязан, и основывает приговор на доказательствах, представленных ему следователем, которые он принимает на веру. Еще большие отступления от уголовно-процессуального метода допускаются при сокращенном дознании (гл. 32-1): здесь значительно упрощается процесс собирания доказательств, много исключений из правил допустимости доказательств, необязательной является проверка каждого доказательства (гл. 32-1 УПК РФ).

Как видно, закон допускает работу с преступлениями, подчас и тяжкими, мягким, упрощенным методом. Но в такой ситуации у органов власти может не оказаться всех необходимых средств: установление обстоятельств дела здесь усложнено, нередко оно сопровождается противодействием; здесь требуются и особые меры воздействия на обвиняемого и даже свидетелей. Всего этого у мягкого метода нет. Результатом такого положения может оказаться судебная ошибка. Думается, что наличие в УПК РФ мягкого метода регулирования не создает достаточных гарантий для правильного применения норм уголовного права.

Таким образом, состояние существующего в настоящее время уголовно-процессуального метода регулирования вряд ли можно признать удовлетворительным. В уголовном процессе должен быть один четко закрепленный жесткий (императивный) метод регулирования. Вся иная деятельность, не требующая применения уголовно-процессуального метода, должна быть отнесена к административному праву. Несомненно, должны 
допускаться смягчения жесткости, однако это должно быть исключением, обоснованным серьезными обстоятельствами.

Причиной неудовлетворительного состояния уголовно-процессуального метода регулирования является объединение в одном законодательном акте, что создает впечатление о наличии единого уголовного процесса, двух разных видов проявления судебной власти в уголовном процессе - правосудия и судебного контроля. Поэтому для улучшения положения следует воздействовать на причину.

Идеальным было бы разделение этих двух видов судебной власти на самостоятельные, осуществляемые разными судебными органами виды деятельности. Хорошим примером может стать деятельность высшего судебного органа РФ - Конституционного Суда, который правосудие (разрешение уголовных дел) не осуществляет, занимаясь только проверкой соответствия правовых актов Конституции РФ, т.е. судебно-контрольной деятельностью. В регионах разделение можно было бы осуществить таким образом (хотя бы в будущем): правосудием должны заниматься суды по уголовным делам, а судебноконтрольные функции должны осуществлять конституционные суды (которые в регионах так и не созданы, несмотря на то, что конституционное правосудие предусмотрено Конституцией Российской Федерации наряду с другими видами судопроизводства). Хотя это предложение заманчиво, однако нельзя не понять, что его реализация в настоящее время нереальна.

В.А. Лазарева предлагает более простую меру: в каждом суде выделить судью, который бы не занимался правосудием, а осуществлял бы только судебно-контрольную функцию; в многочисленных судах для судебного контроля организовать палаты, составы [2. С. 103-104]. Несомненно, это предложение принесло бы положительный результат, однако практически оно также труднореализуемо, поскольку требует немалого увеличения штата судей. Поэтому представляется возможным внести предложение, которое для реализации пока не потребует материальных затрат: структурировать находящиеся сейчас в смешанном состоянии нормы уголовнопроцессуального и конституционного права, отделить их друг от друга, в связи с чем разделить УПК РФ на два раздела - раздел, содержащий нормы о правосудии, и раздел, содержащий нормы о судебном контроле. Такая мера, как представляется, не будучи радикальной (последние в существующих условиях мало реальны), будет оказывать на судей психологическое воздействие, побуждая пользоваться нормами, регулирующими тот вид деятельности, которым судья занимается. В будущем же для обеспечения правильного и более эффективного проявления судебной власти в уголовном процессе необходимо будет принимать радикальные меры.

\section{Лuтература}

1. Бойков А.Д. Третья власть в России. М., 1997. 264 с.

2. Лазарева В.A. Судебная власть и ее реализация в уголовном процессе. Самара : Самар. ун-т, 1999. $136 \mathrm{c}$. 
3. Воскобитова Л.А. Сущностные характеристики судебной власти. Ставрополь : Ставропольсервисшкола, 2003. $150 \mathrm{c}$.

4. Азаров В.А., Таричко И.Ю. Функции судебного контроля в истории, теории и практике уголовного процесса России. Омск : Омск. гос. ун-т, 2004. 379 с.

5. Алексеев С.С. Теория права. М. : Бек, 1995. 320 с.

6. Алексеев С.С. Структура советского права. М. : Юрид. лит., 1975. 264 с.

Sviridov Mikhail K., Tomsk State University (Tomsk, Russian Federation)

JUDICIAL AUTHORITY AND ITS MANIFESTATION IN CRIMINAL TRIALS

Keywords: judicial authority, justice, judicial control.

DOI: $10.17223 / 22253513 / 27 / 9$

After the Constitution of the Russian Federation had entrenched the separation of powers, judicial authority acquired one more function - to serve as a system of checks and balances in relation to other branches of power (judicial control over the legality of investigative bodies' activities). There is no consensus whether judicial control is an independent function or it is a part of justice. It seems certain that judicial control and justice are independent functions of judicial authority. They have different problems, objects and methods of regulation.

Justice decides criminal cases whereas judicial control prevents investigators from going beyond the legal framework. Justice has a tough method of regulation with a detailed legal rulemaking, manifestation of authoritativeness concerning the subjects of criminal trial allowing the application of coercion towards the subjects. Judicial control has a mild regulation method, settled by the law only in general and therefore, allowing a considerable judicial discretion. Authoritativeness manifestation is milder here; application of coercion to subjects is inadmissible. Despite such great differences, both types of judicial activity are in one law, i.e. in the $\mathrm{CC}$ of $\mathrm{RF}$, forming a uniform criminal trial where the elements of different methods are mixed. It is highly unlikely to recognize such a situation to be normal.

Criminal trial is a system the elements of which are not only interconnected, but also exert impact on each other. Being in one system with justice, a considerably milder method of regulation of judicial control can result in the vagueness of justice and this is dangerous for the court when it applies the norms of the toughest branch of law - a criminal one. Some authors propose changing the current situation. The most radical proposal is to divide justice and judicial control between different courts or to retain them in one court but for different judges and to create special court chambers for this purpose.

However, nowadays when fundamental judicial reforms are going on, the realization of radical measures is unreal. Therefore, a minimum measure is proposed: to structure the standards of justice and judicial control and place them in the separate sections of the CC of RF.

\section{References}

1. Boykov, A.D. (1997) Tret'ya vlast' v Rossii [The Third Power in Russia]. Moscow: Research Institute for Strengthening the Rule of Law and Order.

2. Lazareva, V.A. (1999) Sudebnaya vlast' i ee realizatsiya $v$ ugolovnom protsesse [Judicial power and its implementation in the criminal process]. Samara: Samara State University.

3. Voskobitova, L.A. (2003) Sushchnostnye kharakteristiki sudebnoy vlasti [Essential characteristics of the judicial power]. Stavropol': Stavropol'servisshkola.

4. Azarov, V.A. \& Tarichko, I.Yu. (2004) Funktsii sudebnogo kontrolya $v$ istorii, teorii $i$ praktike ugolovnogo protsessa Rossii [Functions of judicial control in the history, theory and practice of the criminal process in Russia]. Omsk: Omsk State University.

5. Alekseev, S.S. (1995) Teoriya prava [The Theory of Law]. Moscow: Bek.

6. Alekseev, S.S. (1975) Struktura sovetskogo prava [The Structure of Soviet Law]. Moscow: Yuridicheskaya literatura. 